\title{
Cólera: Siempre preparados para...
}

\author{
Cholera: Always ready for...
}

Cada cierto período de tiempo, nuestro país registra situaciones de alarma relacionadas con las enfermedades entéricas.

A comienzos de abril de este año, producto de la inadecuada eliminación de basuras en algunos sectores de Antofagasta, se vivió una situación de alerta sanitaria local.

Durante el año 2009 en la Región de Antofagasta, al mes de abril, hubo nueve muestras positivas a cólera no epidémico y este año cuatro; ambas reflejan una situación habitual y no corresponden a casos de cólera epidémico, el que no se observa en Chile desde 1993. Sin embargo, obligan a mantener una vigilancia epidemiológica permanente e insistir en el enfoque preventivo de la enfermedad y no exclusivamente reaccionar frente a situaciones de emergencia; el actuar únicamente de esta última forma sólo previene las muertes y no los casos (OMS).

La historia nos muestra que el cólera ha sido una preocupación en nuestro país desde hace más de 100 años. En 1886 F. Puga Borne publica en el Boletín de Medicina bajo el título “Cómo se evita El Cólera”. Lo define como "una de las enfermedades más tremendas que aquejan a la especie humana". Entonces la causa no estaba aún bien determinada, pero la proximidad de la enfermedad proveniente de Argentina hizo que nuestro país, que hasta entonces no registraba casos, generara una propuesta de cierre de fronteras.

Lo central de este documento es el énfasis en un plan de prevención del cólera y la insistencia en no minimizar sus riesgos. De ahí la importancia del artículo publicado en este número por M. Teresa Valenzuela B. y cols, (pág. 407) quienes revisan los distintos aspectos que tienen relevancia en su enfrentamiento actual. En éste se reitera la necesidad de mantener un enfoque multisectorial, las medidas de higiene personal y ambiental y una vigilancia epidemiológica activa frente a una enfermedad que constituye una amenaza permanente sobre la que debe mantenerse un control mientras siga constituyendo un problema latente de Salud Pública en las distintas regiones del mundo.

\section{Angélica Silva D.}

Directora $(S)$,

Servicio de Salud Metropolitano Oriente Editora, Sección Epidemiología, Revista Chilena de Infectología. 